\title{
Clinical utility of treprostinil in the treatment of pulmonary arterial hypertension: an evidence-based review
}

This article was published in the following Dove Press journal:

Core Evidence

20 June 2014

Number of times this article has been viewed

\author{
Mitchell S Buckley' \\ Andrew J Berry' \\ Nadine $\mathrm{H} \mathrm{Kazem}^{2}$ \\ Shardool A Patel ${ }^{3}$ \\ Paul A Librodo ${ }^{4}$ \\ 'Department of Pharmacy, Banner \\ Good Samaritan Medical Center, \\ Phoenix, AZ, USA; ${ }^{2}$ Department of \\ Pharmacy, St Joseph's Hospital and \\ Medical Center, Phoenix, AZ, USA; \\ ${ }^{3}$ Department of Pharmacy, Banner \\ Estrella Medical Center, Phoenix, \\ AZ, USA; ${ }^{4}$ Department of Pharmacy, \\ San Francisco VA Medical Center, \\ San Francisco, CA, USA
}

\begin{abstract}
Pulmonary arterial hypertension (PAH) remains a progressive disease without a cure, despite the development of several treatment options over the past several decades. Its management strategy consists of the endothelin receptor antagonists (ambrisentan, bosentan, macitentan), phosphodiesterase-5 inhibitors (sildenafil, tadalafil, vardenafil), and prostacyclin analogs (epoprostenol, treprostinil, iloprost). Treprostinil, a stable prostacyclin analog, displays vasodilatory effects in the pulmonary vasculature, as well as antiplatelet aggregation properties. Clinical practice guidelines recommend oral endothelin receptor antagonist or phosphodiesterase inhibitor therapy in mild to moderate PAH. Epoprostenol is specifically suggested as first-line therapy in moderate to severe PAH patients (ie, World Health Organization/New York Heart Association functional class III-IV). However, treprostinil may be an alternative option in these severe PAH patients. The longer half-life and stability at room temperature with treprostinil may be associated with lower risk of pulmonary hemodynamic worsening as a result of abrupt infusion discontinuation and less frequent drug preparation. These characteristics make treprostinil an attractive alternative to continuous infusion of epoprostenol, due to convenience and patient safety. The purpose of this review is to evaluate the safety and efficacy of continuous infusion of treprostinil as well as the inhaled and oral routes of administration in PAH.
\end{abstract}

Keywords: treprostinil, prostacyclin, pulmonary arterial hypertension

\section{Core evidence clinical impact summary}

\begin{tabular}{|c|c|c|}
\hline Outcome measure & Evidence & Implications \\
\hline Disease-oriented evidence & Clinical trials & $\begin{array}{l}\text { Parenteral and inhaled treprostinil have } \\
\text { been shown to be safe and effective in } \\
\text { improving exercise capacity, functional class, } \\
\text { and dyspnea scores } \\
\text { Improved clinical outcomes have not been } \\
\text { consistently demonstrated with oral therapy }\end{array}$ \\
\hline Patient-oriented evidence & Clinical trials & $\begin{array}{l}\text { Parenteral and inhaled treprostinil have } \\
\text { demonstrated improved quality of life, while } \\
\text { oral therapy has not } \\
\text { Adverse events associated with parenteral } \\
\text { and oral therapy should be monitored for } \\
\text { safety and tolerability } \\
\text { Inhaled therapy has been shown to be well } \\
\text { tolerated without serious adverse events }\end{array}$ \\
\hline Economic evidence & None currently & $\begin{array}{l}\text { No formal cost-effective analysis has } \\
\text { been conducted. However, costs should } \\
\text { be considered when selecting a specific } \\
\text { formulation in comparison to other available } \\
\text { PAH therapies }\end{array}$ \\
\hline
\end{tabular}

Correspondence: Mitchell S Buckley Clinical Pharmacy Specialist, Banner Good Samaritan Medical Center, Department of Pharmacy,

II I I E McDowell Rd, Phoenix, AZ 85006, USA

Tel +l 6028393095

Fax +l 6028396734

Email mitchell.buckley@bannerhealth. com 


\section{Introduction}

Pulmonary arterial hypertension $(\mathrm{PAH})$ remains a progressive disease without a cure, despite the development of several treatment options. ${ }^{1}$ The prevalence of PAH varies according to the patient's etiology and is higher in certain populations. ${ }^{2}$ Idiopathic PAH has an annual incidence of one to two cases per million, and scleroderma-associated PAH patients have even higher rates. ${ }^{2,3}$ Clinical manifestations are typically nonspecific, including dyspnea, fatigue, weakness, and low exercise capacity. ${ }^{3}$ Prognostic markers include cardiopulmonary hemodynamics, exercise capacity, and World Health Organization (WHO)/New York Heart Association (NYHA) functional class. ${ }^{4}$ As the disease progresses, death from PAH results from right heart failure. ${ }^{4}$ The estimated natural survival rate is approximately 2.8 years and may improve with medical therapy. ${ }^{5}$

The definition of PAH is a mean pulmonary artery pressure (MPAP) $>25 \mathrm{mmHg}$ at rest. ${ }^{6}$ The clinical classification system endorsed by the WHO is based upon grouping pulmonary hypertension diseases with similar clinical manifestations, pathogenesis, and treatment strategies. ${ }^{7}$ The five groups include 1) PAH, 2) pulmonary hypertension associated with left heart disease, 3) pulmonary hypertension owing to lung diseases and/or hypoxia, 4) chronic thromboembolic pulmonary hypertension, and 5) miscellaneous causes of pulmonary hypertension.

The pathogenesis of PAH may be multifactorial involving increased endothelin-1 (ET-1), decreased production of prostaglandin $\mathrm{I} 2\left(\mathrm{PGI}_{2}\right)$, and decreased nitric oxide (NO). Changes in concentrations of these endogenous compounds can lead to endothelial dysfunction as well as progressive destruction of pulmonary vasculature. ${ }^{8,9}$ Being a potent vasoconstrictor, ET-1 stimulates pulmonary artery smooth muscle cell proliferation while promoting inflammation and fibrosis. ${ }^{8}$ An imbalance of thromboxane $\mathrm{A}_{2}$ compared with $\mathrm{PGI}_{2}$ concentrations may lead to thrombosis, inflammation, and vasoconstriction. ${ }^{10}$ Also, the vasodilatory effects of NO are largely mediated by cyclic guanosine monophosphate, which relaxes vascular smooth muscle. ${ }^{11}$ As each of these mechanisms can play a role in the progression of PAH, it remains unclear which pathway or combinations of pathways are predominant and most critical.

Goals of PAH treatment include improvement in the patient's symptoms, quality of life, and survival. Objective assessments to measure treatment response include improvement in exercise capacity through the 6-minute walk distance (6MWD), cardiopulmonary exercise test, cardiopulmonary hemodynamics, and survival. ${ }^{4}$ To this day, $6 \mathrm{MWD}$ remains a common clinical trial outcome, as it is used to assess the effect of PAH treatments on exercise capacity and, by extension, on disease progression. ${ }^{4}$

Significant advances in the treatment of PAH have been achieved over the past decades. Epoprostenol, a prostacyclin, improves exercise capacity, hemodynamics, and survival in PAH. ${ }^{12,13}$ Other prostacyclins, such as treprostinil and iloprost, have been shown to improve 6MWD and pulmonary pressures. ${ }^{1}$ Endothelin receptor antagonists (ERAs) (bosentan, ambrisentan, and macitentan) have demonstrated improved exercise capacity in PAH. ${ }^{1}$ Phosphodiesterase (PDE)-5 inhibitors (sildenafil, tadalafil, and vardenafil) have yielded improved exercise capacity and hemodynamics in PAH. ${ }^{1}$ The American College of Cardiology and the European Society of Cardiology/European Respiratory Society PAH guidelines recommend subcutaneous (SubQ), intravenous (IV), or inhaled treprostinil in patients with WHO class IV (recommendation evidence IIa-C). ${ }^{14,15}$ Inhaled and SubQ treprostinil are also options in class III (recommendation evidence I-B), and IV treprostinil is a IIa-C recommendation. ${ }^{14,15}$ Overall, treprostinil is a viable option in class III-IV patients. ${ }^{14,15}$ However, IV epoprostenol is the recommended pharmacologic agent for class IV patients. ${ }^{14,15}$ Several clinical trials have evaluated the impact of treprostinil on exercise capacity, hemodynamics, functional class, and survival in PAH patients (Table 1) ${ }^{16-29}$ Treprostinil has also been shown to be safe and effective in various PAH subgroup patient populations, including systemic sclerosis..$^{30}$ The purpose of this review is to provide a critical evaluation of the clinical utility of continuous infusion and novel forms (oral and inhaled) of treprostinil in the management of PAH.

\section{Treprostinil}

Treprostinil is a tricyclic benzidene analog of prostacyclin, exerting antiplatelet and vasodilatory actions, including pulmonary vasodilation. ${ }^{31}$ It is currently commercially available as an injectable for IV or SubQ administration, oral extendedrelease tablets, and inhalation solution. ${ }^{32-34}$ The injectable solution can be reconstituted in sterile water or $0.9 \%$ sodium chloride and is stable at room temperature. ${ }^{32}$ Oral treprostinil is commercially available as $0.125 \mathrm{mg}, 0.25 \mathrm{mg}, 1 \mathrm{mg}$, and $2.5 \mathrm{mg}$ osmotic extended-release tablets administered twice daily (bid).$^{33}$ The recommended starting dose is $0.25 \mathrm{mg}$ orally bid and titrated every 3 days as tolerated. Inhaled treprostinil is administered via ultrasonic nebulizers to decrease particle size, thus allowing drug delivery to distal airways and fibrotic pulmonary arterioles. ${ }^{34}$ The recommended initial inhaled dose is $18 \mu \mathrm{g}$ (ie, three breaths) four times daily. ${ }^{34}$ 


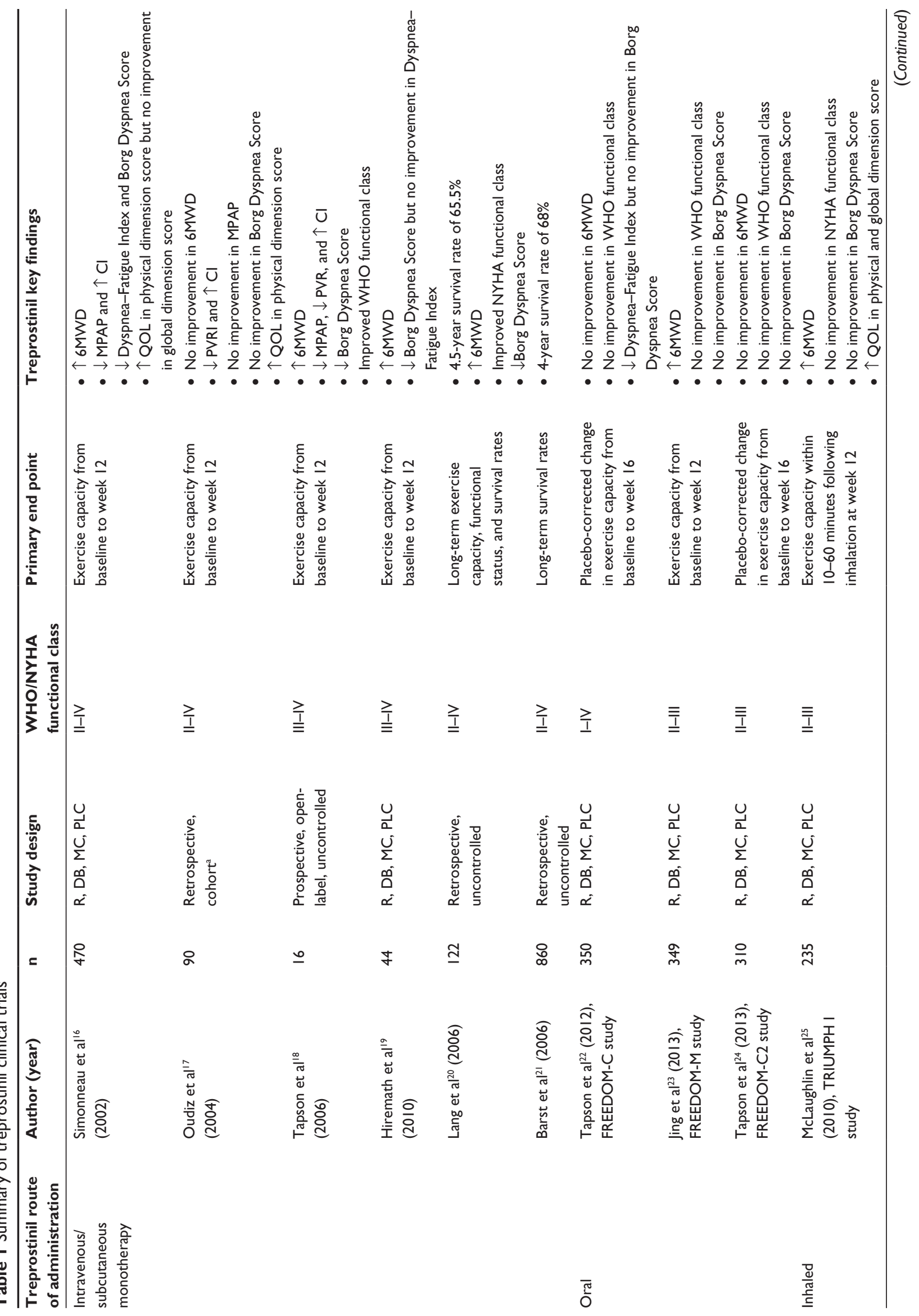




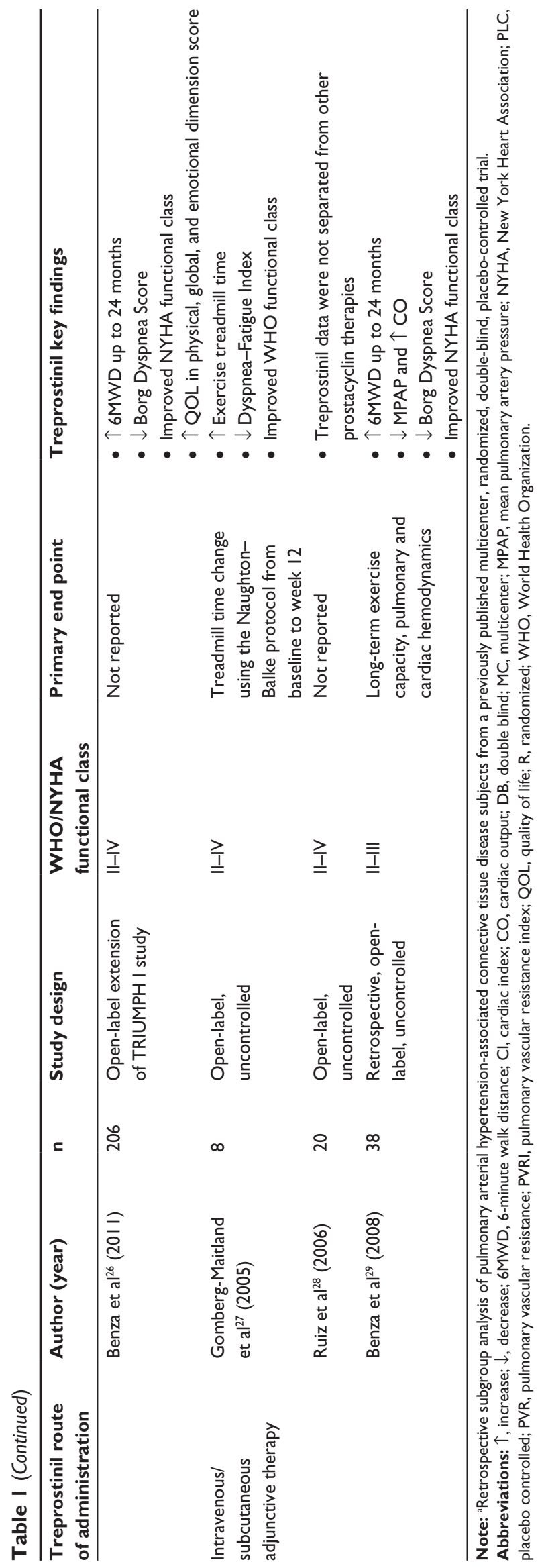

Treprostinil is metabolized through the hepatic system; clearance can be decreased up to $80 \%$ in patients with hepatic insufficiency. ${ }^{32}$ The bioavailability of both the SubQ and IV routes of administration is $100 \%$, and the bioavailability of the oral tablet is about $18 \% .{ }^{35}$ Steady-state plasma concentrations were achieved within 10 hours of continuous infusion rates between $1.25 \mathrm{ng} / \mathrm{kg} / \mathrm{min}$ and $22 \mathrm{ng} / \mathrm{kg} / \mathrm{min}^{32}$ Dose and plasma concentration exhibit a linear relationship for all available formulations. ${ }^{36}$ The half-life of SubQ and IV administration is approximately $2-4$ hours, allowing for nonlife-threatening dose interruptions. ${ }^{32}$ Biphasic elimination results in $79 \%$ of the drug excreted as either unchanged drug $(4 \%)$ or metabolite $(64 \%) .{ }^{32}$ The pharmacokinetic and pharmacodynamic properties of warfarin are not significantly affected with concomitant treprostinil administration..$^{35}$ The regulatory status of this agent significantly varies upon geographic region in the world and the formulation. Parenteral treprostinil has been approved for PAH in several countries in North America, South America, and Europe ${ }^{37}$ The inhaled preparation is approved in the US and Israel, and the oral extended-release tablets are approved for use in the US. ${ }^{37}$

\section{Clinical safety and efficacy Short-term IV/SubQ therapy}

Several trials have been conducted to evaluate the impact of SubQ or IV continuous infusions of treprostinil on exercise capacity and functional class for up to 12 weeks. ${ }^{16-19}$ The first, pivotal study was a randomized, double-blind, multicenter, placebo-controlled trial that investigated the utility of treprostinil continuous SubQ infusion in patients with varying pulmonary hypertension etiologies. ${ }^{16}$ Patients with NYHA functional class II-IV were enrolled with conventional therapy optimized for at least 1 month prior to randomization. After 12 weeks of treprostinil therapy compared with baseline, the 6MWD increased by a median of $10 \mathrm{~m}$ ( $-24 \mathrm{~m}$ to $+47 \mathrm{~m} ; 25$ th-75th percentile) and remained unchanged in the placebo group ( $-44 \mathrm{~m}$ to $+32 \mathrm{~m}$; 25 th75 th percentile). The difference in median distance walked between the two groups was $16 \mathrm{~m}$ (95\% confidence interval [CI]: 4.4-27.6 m, $P=0.006$ ). Following 12 weeks of therapy, the Dyspnea-Fatigue Rating significantly improved to $5.4 \pm 0.2$ from $4.2 \pm 0.1$ at baseline in the treatment group compared with $4.3 \pm 0.1$ from $4.4 \pm 0.1$ at baseline in the placebo group $(P=0.0001)$. In addition, the treprostinil group showed significant improvements from baseline to week 12 in mean right atrial pressure $(-0.5 \pm 0.4 \mathrm{mmHg}$, $P=0.0002)$, MPAP $(-2.3 \pm 0.5 \mathrm{mmHg}, P=0.0003)$, cardiac 
index $\left(+0.12 \pm 0.04 \mathrm{~L} / \mathrm{min} / \mathrm{m}^{2}, P=0.0001\right)$, and mixed venous oxygen saturation $(+2.0 \pm 0.8 \%, P=0.0001)$.

A subgroup analysis of subjects enrolled in the previously mentioned trial by Simonneau et $\mathrm{al}^{16}$ reported outcomes for study subjects with PAH specifically due to underlying connective tissue disease. ${ }^{17}$ The placebo-corrected median improvement in 6MWD at 12 weeks from baseline in the treprostinil group was $25 \mathrm{~m}(P=0.055)$. The improvement in exercise capacity appeared to have been dose dependent. No difference in Borg Dyspnea Score between the treprostinil and placebo groups $(-0.6 \pm 0.5$ and $+0.2 \pm 0.5$, respectively, $P=0.168)$ was found. Although a significant improvement in the cardiac index from baseline of $0.2 \pm 0.08 \mathrm{~L} / \mathrm{min} / \mathrm{m}^{2}(P=0.007)$ was observed in the treprostinil group compared with placebo, this modest increase may not translate into any clinically significant benefit. Furthermore, a significant decrease in pulmonary vascular resistance index was found in treprostinil-treated subjects, whereas the MPAP did not improve.

The first published prospective trial evaluating openlabel IV treprostinil was conducted in PAH patients. ${ }^{18}$ About $87 \%$ of subjects completed the study and showed a significant increase in 6MWD with treprostinil from baseline compared with week $12(319 \pm 22 \mathrm{~m}$ versus $400 \pm 26 \mathrm{~m}$, respectively, $P=0.001)$. The only patient with WHO functional class IV PAH improved to class III, whereas $30 \%$ of patients in class III improved to class II from baseline following 12 weeks of treprostinil. A significant improvement in cardiopulmonary hemodynamics was also noted.

A placebo-controlled, multicenter trial of continuous IV treprostinil was completed in treatment-naïve PAH patients. ${ }^{19}$ The primary outcome was change in 6MWD after 12 weeks of treprostinil treatment. At the end of the study period, the median treprostinil 6MWD was $83 \mathrm{~m}$ greater than the placebo group (95\% CI: 7-187 m, $P=0.008$ ). Although not quite reaching statistical significance, treprostinil appeared to be trending toward beneficial effects according to the DyspneaFatigue Rating when compared with placebo $(P=0.056)$. However, there was a significant improvement in the Borg Dyspnea Score (placebo-corrected difference in the treprostinil group, $2.0 \pm 0.7 \mathrm{~m}, P=0.0089)$. Over $50 \%$ of subjects receiving treprostinil at week 12 showed improved NYHA functional class without any experiencing worsening.

The short-term use of SubQ or IV continuous treprostinil infusion appears to be a viable option in the management of PAH. Several studies showed beneficial effects on exercise capacity, dyspnea, cardiopulmonary hemodynamics, and/or quality of life. ${ }^{16,18,19}$ However, these clinical benefits associated with treprostinil were not consistently corroborated in patients with underlying connective tissue disease-induced PAH. ${ }^{17}$ Therefore, its use in this specific patient population warrants further investigation. Furthermore, all three studies evaluating improved dyspnea scores showed improvement with treprostinil therapy, whereas these scores worsened in the placebo groups. ${ }^{16,17,19}$ IV and SubQ treprostinil both exhibited a dose-related phenomenon. Those subjects receiving doses in the highest quartile achieved an increased 6MWD relative to patients receiving lower doses. Also, those subjects with more severe PAH showed greater improvement.

\section{Long-term IV/SubQ therapy}

Two retrospective, multicenter, uncontrolled trials have investigated the long-term outcomes of treprostinil. ${ }^{20,21}$ The first published report on the safety and efficacy of long-term SubQ treprostinil included subjects with PAH who were considered nonresponders to high-dose calcium channel blocker therapy or inoperable chronic thromboembolic pulmonary hypertension. ${ }^{20}$ Treprostinil was initiated at $1.25-4 \mathrm{ng} / \mathrm{kg} / \mathrm{min}$ and titrated up to a target dose of $20 \mathrm{ng} / \mathrm{kg} / \mathrm{min}$ at 3 months. Further dose escalation was at the discretion of the provider based upon patient symptoms. The mean treprostinil dose was $26.2 \pm 1.2 \mathrm{ng} / \mathrm{kg} / \mathrm{min}$ at year $1,31.9 \pm 1.6 \mathrm{ng} / \mathrm{kg} / \mathrm{min}$ at year 2 , and $39.8 \pm 2.6 \mathrm{ng} / \mathrm{kg} / \mathrm{min}$ at year 3 . The investigators observed a significant improvement in both exercise capacity and functional status with long-term use compared with baseline. The mean 6MWD significantly increased from baseline to 49-54 months following therapy $(305 \pm 11 \mathrm{~m}$ versus $444 \pm 29 \mathrm{~m}$, respectively, $P<0.0001)$. The NYHA functional class was also shown to improve from a mean baseline value of $3.20 \pm 0.04$ to $2.50 \pm 0.34(P<0.0001)$. This improvement was found to persist for up to 36 months. Survival rates following 1 year, 3 years, and 4 years of treprostinil were $88.6 \%$, $70.6 \%$, and $65.6 \%$, respectively. Survival was similar despite the underlying pulmonary hypertension etiology. Infusion site pain was the most common ( $82 \%$ ) adverse drug event (ADE) reported, but only $4.9 \%$ of subjects discontinued therapy. The overall discontinuation rate due to adverse events in the treprostinil group was $10.6 \%$.

A study by Barst et $\mathrm{al}^{21}$ evaluated the impact of SubQ treprostinil on 4-year survival in patients with various etiologies of pulmonary hypertension. This trial was a long-term extension of previously completed clinical trials investigating the short-term effects of treprostinil. ${ }^{16,38}$ Patients in the treprostinil treatment arm of the previous studies were continued on their current SubQ treprostinil infusion upon enrollment into this current trial. Those subjects randomized 
to the placebo group and de novo patients were initiated on treprostinil continuous SubQ infusion at $1.25 \mathrm{ng} / \mathrm{kg} / \mathrm{min}$ with dose escalation for symptom relief. The mean treprostinil dose was $42 \mathrm{ng} / \mathrm{kg} / \mathrm{min}$ for both 3 years and 4 years after commencing treatment. Unfortunately, exercise capacity and functional status were not assessed. Overall, survival rates at years 1, 2, 3, and 4 after treatment were $87 \%, 78 \%, 71 \%$, and $68 \%$, respectively. The survival rate up to 4 years was higher in NYHA functional class II (74\%) compared with class III (70\%). However, survival data were reported only up to 3 years in class IV (52\%). About 7\% experienced serious adverse events, including infusion site infections and pain, hypotension, and dyspnea.

Overall, both trials demonstrated long-term benefits of SubQ treprostinil on exercise capacity, functional class, and survival. ${ }^{20,21}$ Both trials enrolled subjects with NHYA functional class II-IV, with the majority being class III, and allowed open-label treprostinil management titrated at the discretion of the physician based on symptoms. However, the uncontrolled, retrospective nature of these studies is a significant limitation. Although the trial by Lang et $\mathrm{al}^{20}$ excluded the use of concomitant PAH therapies other than anticoagulation, digoxin, diuretics, and calcium channel blockers, Barst et $\mathrm{al}^{21}$ included $15 \%$ of patients who were receiving adjunctive bosentan or sildenafil. Therefore, the survival analysis was not reflective of treprostinil therapy alone. The observed survival rates with SubQ treprostinil were higher than the expected survival and comparable with IV epoprostenol. Treprostinil was well tolerated in both studies, with adverse events consistent with trials evaluating short-term use. Therefore, long-term use may be a viable treatment option to improve clinical outcomes. More robust clinical trials are needed to corroborate these findings.

\section{Oral therapy}

Three randomized, double-blind, placebo-controlled, multicenter trials have been published assessing the efficacy and safety of oral treprostinil. ${ }^{22-24}$ The FREEDOM-C trial required subjects to be taking an oral PDE-5 inhibitor and/ or an ERA prior to randomization. Seventy-six percent of patients had functional class III PAH. Patients initially received $1 \mathrm{mg}$ oral treprostinil bid or matching placebo with dose increased in $1 \mathrm{mg}$ increments, but poor tolerability of study drug necessitated a change to titration protocols, utilizing smaller tablet sizes of $0.25 \mathrm{mg}$ and $0.5 \mathrm{mg}$, which were not initially available. This led to $22 \%$ of patients leaving the study prematurely versus $14 \%$ of placebo patients. Patients who enrolled once all tablet strengths were available started at $0.5 \mathrm{mg}$ bid with dose increases every 3 days as tolerated. The primary end point was median difference in 6MWD at 16 weeks, which was not statistically different between groups (+11 m, 95\% CI: 0.0-22 m, $P=0.07)$. However, patients who were able to tolerate higher doses of treprostinil appeared to achieve larger improvements in 6WMD (dose $<1 \mathrm{mg}$ bid $+4 \mathrm{~m}$ [n=58], 1.25-3.25 mg bid $+18 \mathrm{~m}[\mathrm{n}=49], 3.5-16 \mathrm{mg}$ bid $+34 \mathrm{~m}[\mathrm{n}=52])$.

A follow-up study by Tapson et al attempted to clarify the efficacy and tolerability of oral treprostinil when slowly titrated in combination with other agents (FREEDOM-C2 study). ${ }^{24}$ Similarly to the FREEDOM-C trial, patients were on stable doses of oral PDE-5 inhibitor and/or ERA therapy prior to randomization. A total of 310 patients were randomized to oral treprostinil, starting at $0.25 \mathrm{mg}$ bid with dose increases every 3 days if clinically indicated or matching placebo for 16 weeks. Seventy-three percent of patients were in PAH functional class III. The primary outcome of this study was placebo-corrected Hodges-Lehmann between-treatment median difference in 6MWD at 16 weeks. The side effect profile was similar to the FREEDOM-C and FREEDOM-M trials, with common adverse events including headache, nausea, diarrhea, flushing, vomiting, and jaw pain occurring more frequently in patients receiving oral treprostinil. Although this trial utilized a more conservative and better-tolerated dose titration protocol than FREEDOM-C or FREEDOM-M, it failed to meet the primary end point, with a $+10 \mathrm{~m}$ placebocorrected Hodges-Lehmann between-treatment median difference in 6MWD at 16 weeks $(P=0.089)$. However, it was hampered by a short duration, allowing patients to achieve only a mean dose of $3.1 \mathrm{mg}$ bid, $\leq 25 \%$ of the target dose of $16 \mathrm{mg}$ bid set in the FREEDOM-C trial. It remains unclear whether a longer trial would be able to demonstrate a significant benefit of this medication relative to placebo in respect of 6MWD in patients receiving other oral medications for PAH.

Jing et $\mathrm{al}^{23}$ tested the efficacy of oral treprostinil monotherapy in a randomized, double-blind, placebo-controlled study (FREEDOM-M) featuring 349 patients largely with PAH functional class II (36\%) and class III (61\%). Similarly to the FREEDOM-C trial, high rates of adverse events and a high study dropout rate in the oral treprostinil group necessitated a change in dose for the titration protocol. The starting dose was decreased from $1 \mathrm{mg}$ bid to $0.5 \mathrm{mg}$ bid and was later reduced further to $0.25 \mathrm{mg}$ bid, with dose titrations every 3 days as tolerated. Overall, 33\% of patients from the oral treprostinil group left the study prematurely versus $25 \%$ of placebo patients. Using a modified intention-to-treat 
analysis that included only patients who had access to $0.25 \mathrm{mg}$ tablets at randomization $(\mathrm{n}=228)$, the FREEDOM-M trial demonstrated a statistically significant increase in the median difference in 6MWD at 12 weeks relative to placebo $(+23 \mathrm{~m}$, 95\% CI: 4-41 m, $P=0.0307$ ).

In summary, these trials do not demonstrate a clear longterm benefit nor define the appropriate place in therapy of oral treprostinil. Although monotherapy demonstrated a statistically significant increase in 6MWD, the long titration period and high rate of adverse events may deter many physicians and patients.

\section{Inhaled treprostinil}

In a randomized, double-blind, placebo-controlled, multicenter trial (Clinical Investigation Into Inhaled Treprostinil Sodium in Patients With Severe Pulmonary Arterial Hypertension [TRIUMPH I] study), McLaughlin et $\mathrm{al}^{25}$ analyzed the effects of inhaled treprostinil in patients receiving bosentan or sildenafil for 12 weeks. Subjects were randomized to receive inhaled treprostinil starting at $18 \mu \mathrm{g}$, increasing as tolerated to $54 \mu \mathrm{g}$, four times daily or placebo. The primary outcome was placebo-corrected Hodges-Lehmann between-treatment median difference in 6MWD at 12 weeks. Inhaled treprostinil demonstrated a significant increase in 6MWD versus placebo $(+19 \mathrm{~m}$, $P=0.0001)$. This trial demonstrated that inhaled treprostinil, when added to oral bosentan or sildenafil for 12 weeks, increases 6MWD relative to placebo.

As a follow-up to the TRIUMPH I study, a 2-year, open-label extension of inhaled treprostinil was published. ${ }^{26}$ Patients from the TRIUMPH I study who were still taking bosentan or sildenafil were allowed to receive open-label inhaled treprostinil, starting at $18 \mu \mathrm{g}$ four times daily and increasing to $54 \mu \mathrm{g}$ four times daily as tolerated. At the discretion of the investigator, doses up to $72 \mu \mathrm{g}$ four times daily were allowed. To maintain the blinding of the original trial, all patients, regardless of whether they had previously been assigned to the treprostinil group or the placebo group, were initiated at the starting dose of $18 \mu \mathrm{g}$ four times daily. The median change in 6MWD over time was recorded every 3 months. Median change in 6MWD at 6 months was $+28 \mathrm{~m}$, but some of these gains were not maintained, as median change in $6 \mathrm{MWD}$ fell to $+18 \mathrm{~m}$ after 24 months. This lack of a durable response was attributed to the patients who had been assigned to placebo in the original trial, who appeared to experience greater disease progression than those who were originally assigned to the treprostinil group. Although $41 \%$ of patients withdrew from the trial, this study demonstrates that improvement in 6MWD seen in more short-term trials can be maintained over a period of 2 years. This study also suggests that earlier initiation of treprostinil may yield a better response compared with starting later in the progression of the disease.

Although limited to a single randomized controlled trial, available evidence indicates that inhaled treprostinil can improve 6MWD when added to baseline therapy of bosentan or sildenafil. ${ }^{25}$ However, this therapy is not free of adverse effects, with cough, headache, and flushing being the most commonly observed in trials. Specialized equipment for delivery and four times daily administration may deter some patients from receiving this therapy. Given the limited therapeutic options for patients with PAH and the positive data when used in combination with approved oral therapies, this dosage form holds substantial promise. However, due to the small number of patients who have received the medication in a randomized controlled fashion and the short duration of this study, further clinical data could clarify inhaled treprostinil's place in therapy, particularly as it relates to other formulations of treprostinil.

\section{Combination therapy}

Three studies have evaluated the addition of either an endothelial receptor antagonist or a PDE-5 inhibitor as concomitant PAH pharmacotherapy in patients with existing treprostinil therapy. ${ }^{27-29}$ The clinical utility of oral sildenafil added to a SubQ treprostinil regimen was evaluated in an open-label study. ${ }^{27}$ Adjunctive oral sildenafil titrated to $50 \mathrm{mg}$ three times daily was administered to subjects considered as stable within the 30 days preceding the study while being maintained on an optimal treprostinil dose for $\geq 6$ months. Compared with baseline, the eight patients completing the study demonstrated an increase in treadmill time from $465 \pm 167$ seconds to $656 \pm 205$ seconds $(P=0.049)$ following 12 weeks of concomitant treatment. Three patients improved from WHO functional class III to class II. Typical vasodilator-mediated reactions were observed, specifically headache $(\mathrm{N}=3)$, flushing $(\mathrm{N}=3)$, and jaw pain $(\mathrm{N}=2)$. The mean treprostinil dose (49.9 ng/kg/min) did not change throughout the study duration. Although a greater increase in exercise treadmill time was observed in patients with higher treprostinil dose requirements at baseline, patient-specific parameters such as initial WHO functional class, dosing, and corresponding improvement in exercise time are not provided.

In an open-label study, oral sildenafil was added to existing prostacyclin therapy in subjects with severe $\mathrm{PAH}$ or individuals with the presence of right ventricular dysfunction 
despite PAH functional class. ${ }^{28}$ Oral sildenafil titrated to a target dose of $50 \mathrm{mg}$ three times daily was added when at least two of the following criteria, implying clinical deterioration, were met: 1) NYHA class III-IV, 2) $>20 \%$ decrease in $6 \mathrm{MWD}, 3$ ) syncope, or 4) signs of right ventricular failure despite optimization of volume overload with diuretics. Baseline prostacyclin regimens consisted of IV epoprostenol $(\mathrm{N}=7$, mean dose $21.6 \pm 5.6 \mathrm{ng} / \mathrm{kg} / \mathrm{min})$, SubQ treprostinil $(\mathrm{N}=8$, mean dose $31.7 \pm 6.4 \mathrm{ng} / \mathrm{kg} / \mathrm{min})$, and aerosolized iloprost $(\mathrm{N}=5$, mean dose $140 \pm 22.4 \mu \mathrm{g} /$ day $)$. A statistically significant improvement in 6MWD compared with baseline $(350.6 \pm 121 \mathrm{~m})$ was observed at 1 year, $429.7 \pm 86$ $\mathrm{m}(P=0.02)$, and 2 years, $455.6 \pm 89.4 \mathrm{~m}(P=0.04$ versus 1 year). Heart failure symptoms, reported by $55 \%$ of study subjects prior to combination therapy, decreased to $16 \%$ after 1 year. The mean prostacyclin doses after 2 years of concomitant therapy increased to $26 \pm 6.4 \mathrm{ng} / \mathrm{kg} / \mathrm{min}$ for epoprostenol, $46.3 \pm 14.3 \mathrm{ng} / \mathrm{kg} / \mathrm{min}$ for treprostinil, and $150 \mu \mathrm{g} /$ day for iloprost. Five study subjects did not complete the follow-up at 2 years and two patients died during the follow-up period. This study demonstrates potential for improvement in hemodynamics and functional capabilities when combined therapy is administered to subjects regressing with monotherapy. However, respective increases in the mean prostacyclin doses observed during the study period for all three agents lead us to question whether the benefit of combination therapy is derived from the addition of sildenafil or escalation in prostacyclin dosing.

The long-term safety and efficacy of bosentan added to SubQ treprostinil therapy was evaluated in a retrospective, open-label study. ${ }^{29}$ Study subjects demonstrating a lack of clinical progress with treprostinil monotherapy, defined as persistent NYHA functional class III $(\mathrm{N}=12)$ or NYHA functional class II requiring dose reductions due to adverse effects of prostacyclin therapy $(\mathrm{N}=7)$, were eligible for the addition of oral bosentan titrated to $125 \mathrm{mg}$ bid. A statistically significant improvement in MPAP compared with baseline $(59.7 \pm 15.1 \mathrm{mmHg})$ was observed prior to the start of bosentan therapy, $55.7 \pm 15.7 \mathrm{mmHg}(P<0.001)$, and at the time of final follow-up, $47.2 \pm 11.6 \mathrm{mmHg}(P<0.001$ versus prebosentan). Similarly, the baseline 6MWD of $307.2 \pm 58.9 \mathrm{~m}$ increased to $332.8 \pm 79.6 \mathrm{~m}$ before initiating bosentan $(P<0.001)$ and $374.2 \pm 110.3 \mathrm{~m}$ at the final observation $(P=0.071$ versus prebosentan). The mean treprostinil infusion rate increased from $38 \mathrm{ng} / \mathrm{kg} / \mathrm{min}$ at the time of starting bosentan to $44.4 \mathrm{ng} / \mathrm{kg} / \mathrm{min}$ at the time of final evaluation. Concomitant therapy was well tolerated; however, statistically significant reductions in liver transaminases and hemoglobin compared with baseline were observed. Although the results of this study suggest clinical benefit in pulmonary hemodynamics and functional capacity with combination therapy, it remains unclear whether the advantage was due to the addition of a second agent and/or progressive increase in treprostinil dose observed through the study period.

These three studies suggest possible improvement from combination therapy in pulmonary and functional capabilities. ${ }^{27-29}$ Each study featured a limited sample size. Two studies demonstrate benefits in 6MWD and pulmonary hemodynamics when combination therapy is utilized in subjects with poorer prognostic markers. ${ }^{28,29}$ Both studies are difficult to interpret, as doses of treprostinil increased during the study period. ${ }^{28,29}$ Most patients in these trials were functional class III or IV PAH. The possible risks and benefits of combination therapy in patients with less severe PAH remain debatable.

\section{Safety and tolerability Safety}

Common ADEs associated with IV and SubQ treprostinil therapy include nausea, headache, diarrhea, flushing, jaw pain, and infusion site-related pain. ${ }^{32}$ Infusion site-related pain may occur in up to $90 \%$ of patients. ${ }^{16,21}$ Most reported cases of jaw or infusion site pain were considered benign and transient. ${ }^{16,18,20,21}$ Serious ADEs associated with continuous infusion of treprostinil have been reported as infusion site pain, systemic hypotension, syncope, and dyspnea. ${ }^{16,18,20,21}$ Fortunately, the most common serious ADE reported in most trials has been infusion site pain, with an incidence of $<8 \%{ }^{16,18,21}$ Continuous infusion of treprostinil delivered via an indwelling catheter may also increase the risk of infection. ${ }^{32}$ One study reported a high rate of serious ADEs with treprostinil SubQ infusions. ${ }^{19}$ Hiremath et al ${ }^{19}$ reported that $30 \%$ of treprostinil subjects developed sepsis or an infection, possibly as a result of an indwelling catheter. No significant difference in mortality rates was found between treprostinil and placebo. Nonetheless, an independent safety committee decided to suspend study enrollment and eventually terminated the trial due to serious adverse events and concern about the risk outweighing any benefit. It remains speculative whether the serious deleterious events were truly attributed to treprostinil or related to the overall patient care conditions in a developing country. Inhaled treprostinil is also associated with ADEs, with cough being the most common in over $50 \%$ of subjects. ${ }^{26}$ Headache, flushing, and nausea are other common ADEs. ${ }^{26}$ Fortunately, no serious adverse effects have been reported with the inhaled route of administration. The oral formulation appears to have higher incidence of ADEs, 
with headache $(69 \%-86 \%)$, nausea $(39 \%-73 \%)$, diarrhea (37\%-87\%), flushing (21\%-55\%), and pain being commonly observed in the trials. ${ }^{22-24}$ ADEs may be reduced by starting at a low dose, such as $0.25 \mathrm{mg}$ bid, and slowly titrating oral treprostinil. ${ }^{24}$

\section{Tolerability}

Overall, continuous infusion of treprostinil appears to be well tolerated. ${ }^{16,20,21}$ Discontinuation rates resulting from continuous infusion of treprostinil are about $5 \%-8 \%$. $^{16,20,21}$ The most commonly reported reason for discontinuation of IV or SubQ therapy was due to pain from either the infusion site or another location. Patients administered inhaled and oral treprostinil have higher discontinuation rates. One trial found that $72 \%$ of patients in the inhaled treprostinil group were able to achieve the maximum dose of $54 \mu \mathrm{g}$ four times daily. ${ }^{25}$ Another trial found that $100 \%$ of patients achieved the target dose of $54 \mu \mathrm{g}$ four times daily, with $40 \%$ tolerating the maximum dose of $72 \mu \mathrm{g}$ four times daily. ${ }^{26}$ Unfortunately, $41 \%$ of patients dropped out of the study, $17 \%$ due to adverse effects. ${ }^{26}$ Tolerability with the oral dosage form appears problematic, requiring careful titration over a long period of time. ${ }^{22-24}$ The overall rate of subjects prematurely discontinuing study drug was similar in the oral treprostinil and placebo groups for both the intention to treat ( $22 \%$ versus $23 \%$, respectively) and modified intention to treat ( $17 \%$ versus $14 \%$, respectively). ${ }^{23}$ However, comparing the dropout rate for subjects as a result of a possible ADE attributed to the study medication was about $2 \%$ in the placebo group. ${ }^{23}$ Discontinuation rates secondary to adverse events in the $1 \mathrm{mg}$ bid treprostinil arm was about $10 \%$ (intention to treat) compared with only $4 \%$ (modified intention to treat) in patients starting therapy at lower doses. ${ }^{23}$ This finding may suggest that patients initiated on oral treprostinil therapy at lower doses $(0.25 \mathrm{mg}$ or $0.5 \mathrm{mg})$ may tolerate therapy initially and during dose escalations. ${ }^{23}$ It is conceivable that if high doses are achieved, this medication may provide substantial benefit in 6MWD, but as current trials have been limited to 16 weeks, none has been able to demonstrate benefit when used in combination with other medications.

\section{Conclusion}

Treprostinil administered via the IV or SubQ route has been shown to be a safe and efficacious therapeutic option in the management of PAH. Clinical studies have demonstrated improved exercise capacity, functional class, and clinical symptoms for both short- and long-term use. Concomitant treprostinil SubQ therapy with ERA or PDE-5 inhibitor therapy has also shown promise in improving exercise capacity and cardiopulmonary hemodynamics. Although inhaled treprostinil has been found to increase exercise capacity and quality of life, this route of administration failed to consistently improve clinical symptoms, functional class, and cardiopulmonary hemodynamics in clinical trials. The role of oral treprostinil therapy in PAH remains unclear, with a benefit found only when used as monotherapy, whereas adjunctive therapy failed to improve clinical or functional status. Tolerability appears to be a significant concern with oral treprostinil. Overall, treprostinil remains a viable treatment strategy in $\mathrm{PAH}$ with several available routes of administration.

\section{Disclosure}

The authors report no conflicts of interest in this work.

\section{References}

1. Barst RJ, Gibbs JS, Ghofrani HA, et al. Updated evidence-based treatment algorithm in pulmonary arterial hypertension. J Am Coll Cardiol. 2009;54(Suppl 1):S78-S84.

2. D'Alonzo GE, Barst RJ, Ayres SM, et al. Survival in patients with primary pulmonary hypertension: results from a national prospective registry. Ann Intern Med. 1991;115(5):343-349.

3. Chin KM, Rubin LJ. Pulmonary arterial hypertension. J Am Coll Cardiol. 2008;51(16):1527-1538.

4. Badesch DB, Champion HC, Gomez-Sanchez MA. Diagnosis and assessment of pulmonary arterial hypertension. J Am Coll Cardiol. 2009;54(Suppl 1):S55-S66.

5. Fuster V, Steele PM, Edwards WD, et al. Primary pulmonary hypertension: natural history and the importance of thrombosis. Circulation. 1984;70(4):580-587.

6. Hoeper MM, Bogaard HJ, Condliffe R, et al. Definitions and diagnosis of pulmonary hypertension. $J$ Am Coll Cardiol. 2013;62(25): D42-D50.

7. Simonneau G, Gatzoulis MA, Adatia I, et al. Updated clinical classification of pulmonary hypertension. J Am Coll Cardiol. 2013;62(25): D34-D41.

8. McLaughlin VV, Archer SL, Badesch DB et al. ACCF/AHA 2009 expert consensus document on pulmonary hypertension: a report of the American College of Cardiology Foundation Task Force on Expert Consensus Documents and the American Heart Association developed in collaboration with the American College of Chest Physicians; American Thoracic Society, Inc.; and the Pulmonary Hypertension Association. J Am Coll Cardiol. 2009;53(17):1573-1619.

9. Humbert M, Morrell NW, Archer SL, et al. Cellular and molecular pathobiology of pulmonary arterial hypertension. J Am Coll Cardiol. 2004;43(Suppl 12):13S-24S.

10. Christman BW, McPherson CD, Newman JH, et al. An imbalance between the excretion of thromboxane and prostacyclin metabolites in pulmonary hypertension. $N$ Engl J Med. 1992;327(2):70-75.

11. Steudel W, Ichinose F, Huang PL, et al. Pulmonary vasoconstriction and hypertension in mice with targeted disruption of the endothelial nitric oxide synthase (NOS 3) gene. Circ Res. 1997;81(1): 34-41.

12. Barst RJ, Rubin LJ, Long WA, et al. A comparison of continuous intravenous epoprostenol (prostacyclin) with conventional therapy for primary pulmonary hypertension. $N$ Engl J Med. 1996;334(5): 296-301. 
13. Sirbon O, Humbert M, Nunes $H$, et al. Long-term intravenous epoprostenol infusion in primary pulmonary hypertension: prognostic factors and survival. J Am Coll Cardiol. 2002;40(4):780-788.

14. Galie N, Hoeper MM, Humbert M, et al. Guidelines for the diagnosis and treatment of pulmonary hypertension: the Task Force for the Diagnosis and Treatment of Pulmonary Hypertension of the European Society of Cardiology (ESC) and the European Respiratory Society (ERS), endorsed by the International Society of Heart and Lung Transplantation (ISHLT). Eur Heart J. 2009;30(20):2493-2537.

15. Galie N, Corris PA, Frost A, et al. Updated treatment algorithm of pulmonary arterial hypertension. J Am Coll Cardiol. 2013; 62(Suppl D):D60-D72.

16. Simonneau G, Barst RJ, Galie N, et al. Continuous SubQ infusion of treprostinil, a prostacyclin analogue, in patients with pulmonary arterial hypertension: a double-blind, randomized, placebo-controlled trial. Am J Respir Crit Care Med. 2002;165(6):800-804.

17. Oudiz RJ, Schilz RJ, Barst RJ, et al. Treprostinil, a prostacyclin analogue, in pulmonary arterial hypertension associated with connective tissue disease. Chest. 2004;126(2):420-427.

18. Tapson VF, Gomberg-Maitland M, McLaughlin VV, et al. Safety and efficacy of IV treprostinil for pulmonary arterial hypertension: a prospective, multicenter, open-label, 12-week trial. Chest. 2006;129(3): 683-688.

19. Hiremath J, Thanikachalam S, Parikh K, et al. Exercise improvement and plasma biomarker changes with IV treprostinil therapy for pulmonary arterial hypertension: a placebo-controlled trial. J Heart Lung Transplant. 2010;29(2):137-149.

20. Lang I, Gomez-Sanchez M, Kneussl, et al. Efficacy of long-term SubQ treprostinil sodium therapy in pulmonary hypertension. Chest. 2006;129(6):1636-1643.

21. Barst RJ, Galie N, Naeije R, et al. Long-term outcome in pulmonary arterial hypertension patients treated with SubQ treprostinil. Eur Respir J. 2006;28(6):1195-1203.

22. Tapson VF, Torres F, Kermeen F, et al. Oral treprostinil for the treatment of pulmonary arterial hypertension in patients on background endothelin receptor antagonist and/or phosphodiesterase type 5 inhibitor therapy (the FREEDOM-C study). Chest. 2012;142(6):1383-1390.

23. Jing ZC, Parikh K, Pulido T, et al. Efficacy and safety of oral treprostinil monotherapy for the treatment of pulmonary arterial hypertension. Circulation. 2013;127(5):624-633.

24. Tapson VF, Jing ZC, Xu KF, et al. Oral treprostinil for the treatment of pulmonary arterial hypertension in patients receiving background endothelin receptor antagonist and phosphodiesterase type 5 inhibitor therapy (the FREEDOM-C2 study). Chest. 2013;144(3):952-958.
25. McLaughlin VV, Benza RL, Rubin LJ, et al. Addition of inhaled treprostinil to oral therapy for pulmonary arterial hypertension. J Am Coll Cardiol. 2010;55(18):1915-1922.

26. Benza RL, Seeger W, McLaughlin VV, et al. Long-term effects of inhaled treprostinil in patients with pulmonary arterial hypertension: the treprostinil sodium inhalation used in the management of pulmonary arterial hypertension (TRIUMPH) study open-label extension. J Heart Lung Transplant. 2011;30(12):1327-1333.

27. Gomberg-Maitland M, McLaughlin V, Gulati M, Rich S. Efficacy and safety of sildenafil added to treprostinil in pulmonary hypertension. Am J Cardiol. 2005;96(9):1334-1336.

28. Ruiz M, Escribano P, Delgado J, et al. Efficacy of sildenafil as a rescue therapy for patients with severe pulmonary arterial hypertension and given long-term treatment with prostanoids: 2-year experience. J Heart Lung Transplant. 2006;25(11):1353-1357.

29. Benza RL, Rayburn BK, Tallaj JA, Pamboukian SV, Bourge RC. Treprostinil-based therapy in the treatment of moderate-to-severe pulmonary arterial hypertension: long-term efficacy and combination with bosentan. Chest. 2008;134(1):139-145.

30. Mudaca G, Spano F, Puppo F. Current therapies for the treatment of systemic sclerosis-related pulmonary arterial hypertension: efficacy and safety. Expert Opin Drug Saf. 2014;13(3):295-305.

31. Vachiery JL, Naeije R. Treprostinil for pulmonary hypertension. Expert Rev Cardiovasc Ther. 2004;2(2):183-191.

32. Remodulin ${ }^{\circledR}$ (treprostinil) [package insert]. Research Triangle Park, NC: United Therapeutics Corporation; 2013.

33. Orenitram ${ }^{\mathrm{TM}}$ (treprostinil) extended-release tablets for oral administration [package insert]. Research Triangle Park, NC: United Therapeutics Corporation; 2013.

34. Tyvaso ${ }^{\circledR}$ (treprostinil) inhalation solution [package insert] Research Triangle Park, NC: United Therapeutics Corporation; 2013.

35. Wade M, Hunt TL, Lai AA. Effect of continuous SubQ treprostinil therapy on the pharmacodynamics and pharmacokinetics of warfarin. J Cardiovasc Pharmacol. 2003;41(6):908-915.

36. McSwain CS, Benza R, Shapiro S, et al. Dose proportionality of treprostinil sodium administered by continuous subcutaneous and intravenous infusion. J Clin Pharmacol. 2008;48(1):19-25.

37. Torres F, Rubin LJ. Treprostinil for the treatment of pulmonary arterial hypertension. Expert Rev Cardiovasc Ther. 2013;11(1):13-25.

38. McLaughlin VV, Gaine SP, Barst RJ, et al. Efficacy and safety of treprostinil: an epoprostenol analogue for primary pulmonary hypertension. J Cardiovasc Pharmacol. 2003;41(3):293-299.
Core Evidence

\section{Publish your work in this journal}

Core Evidence is an international, peer-reviewed open-access journal evaluating the evidence underlying the potential place in therapy of drugs throughout their development lifecycle from preclinical to postlaunch. The focus of each review is to evaluate the case for a new drug or class in outcome terms in specific indications and patient groups.

\section{Dovepress}

The manuscript management system is completely online and includes a very quick and fair peer-review system, which is all easy to use. Visit http://www.dovepress.com/testimonials.php to read real quotes from published authors. 